\title{
$\mathrm{Sm}-\mathrm{Fe}$ 薄膜の磁歪特性に及ぼす窒素ガス添加の影響
}

\author{
松 岡 範 佳 $1, * 1$ 田中丸天兵,*22 松 村 義 人 $^{2}$
}

\author{
1東海大学大学院工学研究科応用理学専攻 \\ 東海大学工学部応用理学科 \\ J. Japan Inst. Metals, Vol. 70, No. 3 (2006), pp. 243-245 \\ (C) 2006 The Japan Institute of Metals
}

\section{Effects of N Addition on Magnetostrictive Property of Sm-Fe Thin Film}

\author{
Noriyoshi Matsuoka ${ }^{1, * 1}$, Tempei Tanakamaru ${ }^{2, * 2}$ and Yoshihito Matsumura ${ }^{2}$ \\ ${ }^{1}$ Department of Applied Science, Graduate School of Engineering, Tokai University, Hiratsuka 259-1292 \\ ${ }^{2}$ Department of Applied Science, School of Engineering, Tokai University, Hiratsuka 259-1292
}

\begin{abstract}
$\mathrm{Sm}-\mathrm{Fe}$ thin films as giant magnetostrictive materials were prepared by d.c. magnetron sputtering process with Ar or mixed Ar- $\mathrm{N}_{2}$ gas. Diffraction peaks of Sm nitride and Fe nitride were observed at $3.8 \times 10^{-3} \mathrm{~Pa} \mathrm{~N}_{2}$ partial pressure. With increasing $\mathrm{N}_{2}$ partial pressure, saturated magnetostriction of the $\mathrm{Sm}-\mathrm{Fe}$ thin films decreased from $1400 \mathrm{ppm}$ to $600 \mathrm{ppm}$. The maximum value of magnetostrictive susceptibility was showed at $2.3 \times 10^{-3} \mathrm{~Pa}$ of $\mathrm{N}_{2}$ partial pressure. A compression stress with a small addition of $\mathrm{N}$ into $\mathrm{Sm}-\mathrm{Fe}$ thin films may lead to increase of magnetostrictive susceptibility.
\end{abstract}

(Received November 24, 2005; Accepted January 31, 2006)

Keywords: nitrogen gas, samarium-iron, giant magnetostriction, thin film, magnetron sputtering

\section{1. 緒言}

$\mathrm{TbFe}_{2}$ や, $\mathrm{SmFe}_{2}, \mathrm{~Tb}-\mathrm{Dy}-\mathrm{Fe}$ に代表される希土類一鉄系 のラーベス C15 型金属間化合物は $1000 \mathrm{ppm}$ 以上の磁歪量 を示すことから超磁歪材料 (GMM) と呼ばれており1), アク チュエータ材料として更なる応用が期待されている．超磁歪 材料は圧電材料や形状記憶合金といった，他のアクチュエー タ材料と比べ低電圧での駆動や非接触動作が可能であり, 高 い発生応力や高速の応答性など優れた特性を持っている. た非晶質超磁丕材料薄膜 $(\mathrm{Tb}-\mathrm{Fe}, \mathrm{Sm}-\mathrm{Fe}, \mathrm{Tb}-\mathrm{Dy}-\mathrm{Fe})$ は $\mathrm{GMM}$ と同様に $1000 \mathrm{ppm}$ 以上の巨大な磁歪を示し, デバイ スの小型化かつ軽量化が可能である事から, マイクロマシン のアクチュエータ・センサー材料や表面弾性波素子など広い 用途への応用が期待できる2,3). これまで超磁歪材料薄膜の 研究は様々な成膜プロセスにより行われており, 成膜プロセ スや成膜条件によりその磁気特性が強い影響を受けることが 知られている ${ }^{4-9)}$. 上記の応用においては, 超磁歪材料薄膜 に対して大きな飽和磁歪量や高い磁歪感受率が求められる. スパッタリング法により作製された薄膜では，作製条件によ り引張りから圧縮まで様々な内部応力を示すことが知られて いる10). 内部応力は超磁歪材料薄膜の磁歪感受率に影響を 及ぼす事が知られており11), 内部応力を制御する事により 磁歪特性の向上が期待できる. また, $\mathrm{Sm}-\mathrm{Fe}$ 薄膜を成膜後 にイオン照射を行い, 圧縮の内部応力を増加させ, 磁歪感受

*1 東海大学大学院生 (Graduate Student, Tokai University)

*2 東海大学学生(Undergraduate Student, Tokai University)
率の向上を得たという報告もされている12).

Lim らは, Sm-Fe 薄膜にホウ素を添加して原子間距離を 制御する事によって, 磁歪感受率の向上が可能であることを 報告している13). 高い飽和磁化を示す $\mathrm{Fe}-\mathrm{N}$ 薄膜や, 強力な $\mathrm{Sm}-\mathrm{Fe}-\mathrm{N}$ 磁石に見られるように, 窒素の添加は磁気特性を 向上させる可能性がある. 窒素ガスはスパッタガスとして用 いて薄膜中に窒素を添加することが可能であり, 内部応力の 調整により磁歪感受率の向上が期待できる.

本件究では，スパッタガスに $\mathrm{Ar}, \mathrm{N}_{2}$ を用いることによっ て窒素ガスを添加した Sm-Fe 薄膜を作製し, 磁歪特性への 影響を検討する事を目的とした.

\section{2. 実 験 方 法}

\section{$2.1 \mathrm{Sm}-\mathrm{Fe}$ 薄膜の作製}

$\mathrm{Sm}-\mathrm{Fe}$ 薄膜は DC マグネトロンスパッタ装置を用いて作 製した。 スパッタリングターゲットには直径 $\phi 75 \mathrm{~mm}$ の $\mathrm{SmFe}_{2}$ 合金を用い, ターゲットー基板間距離を $60 \mathrm{~mm}$ とし た. 到達真空度は $7.0 \times 10^{-5} \mathrm{~Pa}$ 以下とし, Ar ガスを導入後 ターゲット清浄化のため $100 \mathrm{~W} て ゙ 10$ 分間プレスパッタを行 った．スパッタガスとして混合ガスを導入し， $1.0 \times 10^{-1}$ $\mathrm{Pa}, 100 \mathrm{~W}$ の条件で 60 分間成膜した. Ar と N の純度はそ れぞれ 99.999\%， 99.9999\%であった. スパッタガスは質量 分析計により分圧測定を行い, マスフローコントローラによ り流量制御した．混合ガスの窒素ガス分圧 $P_{\mathrm{N}_{2}}$ は $2.3 \times 10^{-3}$ $\mathrm{Pa}, 3.8 \times 10^{-3} \mathrm{~Pa}$ とした. 基板には単結晶 $\mathrm{n}$ 型 $\mathrm{Si}(100)(5 \times$ $25 \times 0.28 \mathrm{~mm}$ ) を使用し, 基板温度は $350 \mathrm{~K}$ とした。 


\section{2 評価方法}

作製した薄膜の厚みは触針式表面粗さ計にて測定した．試 料の組成分析はエネルギー分散型 X 線分光法 (EDX)を用い て行い, 構造解析には X 線回折 (XRD), 磁化測定には試料 振動型磁力計 (VSM) を用いて測定した。薄膜面内方向の磁 歪 $\Delta \lambda_{/ /}$は $\mathrm{He}-\mathrm{Ne} レ$ レ゙を利用した光てこ法により測定した 薄膜の反りから次式に示すように求めた ${ }^{14)}$.

\section{3. 実験結果ならびに考察}

\subsection{EDX 測定, XRD 測定結果}

$\mathrm{DC}$ マグネトロンスパッタ法を用いて作製した Sm-Fe 薄 膜の組成は $1 \mathrm{at} \%$ 前後の誤差を含み, $\mathrm{Sm}_{27} \mathrm{Fe}_{73}$ であった.

Fig. 1 に窒素分圧を変化させた $\mathrm{Sm}_{27} \mathrm{Fe}_{73}$ 薄膜の $\mathrm{X}$ 線回折 像を示す，XRD に用いた X 線の波長は $\mathrm{Cu}-\mathrm{K} \alpha$ であった. $\mathrm{Ar}$ ガスのみ抢よび, 窒素ガス分圧 $P_{\mathrm{N}_{2}}$ を $2.3 \times 10^{-3} \mathrm{~Pa}, 3.8$ $\times 10^{-3} \mathrm{~Pa}$ と変化させて作製した全ての薄膜は $\mathrm{Sm}$ 酸化物 ピークや Sm 窒化物ピークを除けば明瞭な回折パターンを示 さなかった.これまでの研究報告から, 明確な回折パターン を示さない希土類一鉄系超磁歪材料薄膜を透過電子顕微鏡で 観察した結果, 非晶質ないし微結晶の集合体であった事が報 告されており, 本研究で作製した $\mathrm{Sm}-\mathrm{Fe}$ 薄膜も主に非晶質 構造を持つ, 非晶質ないし $\mathrm{Sm}-\mathrm{Fe}$ 微結晶の集合体であると 推測される ${ }^{15)} . P_{\mathrm{N}_{2}}=3.8 \times 10^{-3} \mathrm{~Pa}$ において成膜した薄膜は, $\mathrm{Sm}$ 酸化物, $\mathrm{Sm}$ 窒化物, $\mathrm{Fe}$ 窒化物パターンが確認された. $\mathrm{Sm}$ 酸化物は成膜中の蒸着槽内の水蒸気 (分圧 $1.0 \times 10^{-5} \mathrm{~Pa}$ 程度)によって成膜時に生じたものと, 成膜から XRDによ る測定までの間に大気中で $\mathrm{Sm}$ 酸化物が生成したと考えられ る.

\section{$3.2 \mathrm{Sm}-\mathrm{Fe}$ 薄膜の磁歪特性}

次に窒素分圧と磁歪特性の関係を Fig. 2 に示す. Ar ガス のみで作製した $\mathrm{Sm}_{27} \mathrm{Fe}_{73}$ 薄膜は, 最も大きな磁歪量を示 し, 飽和磁歪量は約 $-1400 \mathrm{ppm}$ であった。 また, 飽和磁歪

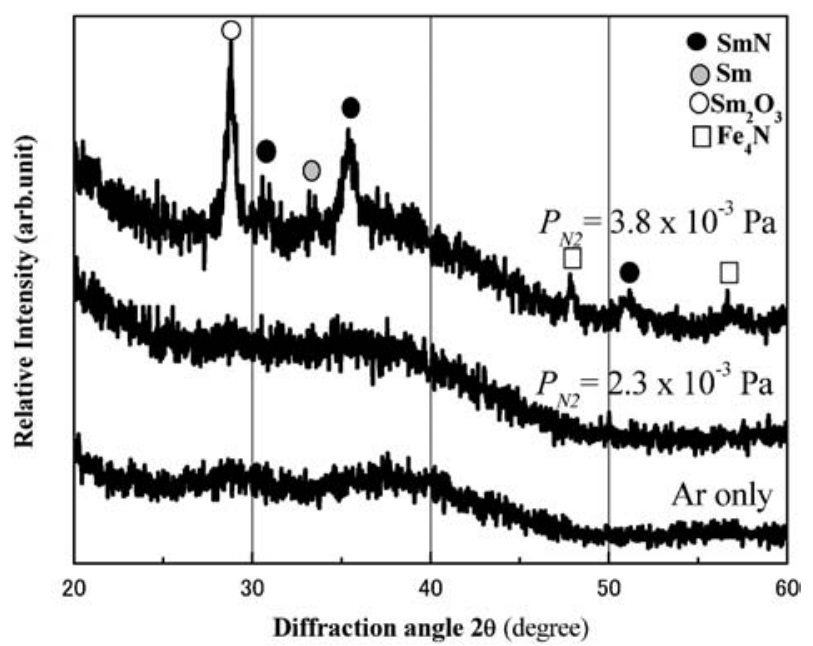

Fig. 1 XRD patterns of $\mathrm{Sm}_{27} \mathrm{Fe}_{73}$ thin films prepared at different $\mathrm{N}_{2}$ partial pressure $P_{\mathrm{N}_{2}}$.
量は $P_{\mathrm{N}_{2}}$ の増加と共に減少した. XRD の結果から, $P_{\mathrm{N}_{2}}$ の増 加により窒化物や酸化物のパターンが確認された事から, 磁 歪現象に寄与する $\mathrm{Sm}_{27} \mathrm{Fe}_{73}$ 薄膜の $\mathrm{Sm}$ 組成が全体として減 少したため, 飽和磁丕量が減少したと考えられる16).

Fig. 3 に各窒素ガス分圧における磁歪感受率を示す. 磁歪 感受率は $P_{\mathrm{N}_{2}}=2.3 \times 10^{-3} \mathrm{~Pa}$ で成膜した $\mathrm{Sm}_{27} \mathrm{Fe}_{73}$ 薄膜にお いて最も高い值を示した。

Fig. 4 に示すように, 磁化測定の結果から垂直磁気異方性 エネルギーを求めた. $\mathrm{Ar}$ ガスのみから $P_{\mathrm{N}_{2}}=2.3 \times 10^{-3} \mathrm{~Pa}$ に変化させた際の垂直磁気異方性エネルギーの変化 $\Delta E_{\mathrm{me}}$ は $\Delta E_{\mathrm{me}}=-2.6 \times 10^{4} \mathrm{~J} / \mathrm{m}^{3}$ であり, 面垂直から面内に磁化が容 易となったことが確認された.

磁気弾性エネルギー $E_{\mathrm{me}}$ は飽和磁歪量 $\lambda_{\mathrm{s}}$ 内部応力 $\sigma$ を用 いて $E_{\mathrm{me}}=-3 / 2 \lambda_{\mathrm{s}} \sigma$ で表される事が知られている ${ }^{17)}$. 非晶 質希土類一鉄系超磁歪材料薄膜は磁歪定数 $\lambda_{\mathrm{s}}$ が他の材料にく らべて約 100 倍大きいため, 内部応力による磁気異方性へ の寄与が大きい. また, 垂直磁気異方性エネルギーの変化 は, 磁気弾性エネルギーの変化に等しいことが報告されてお り, 磁気弾性エネルギーの変化が磁気特性に影響を与え

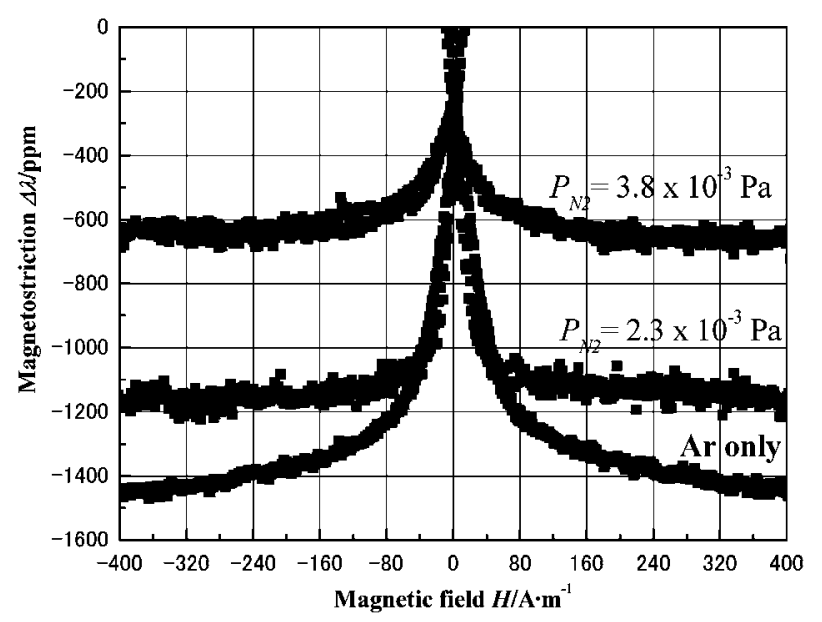

Fig. 2 Magnetstorction of $\mathrm{Sm}_{27} \mathrm{Fe}_{73}$ thin films prepared at different $\mathrm{N}_{2}$ partial pressure $P_{\mathrm{N}_{2}}$.

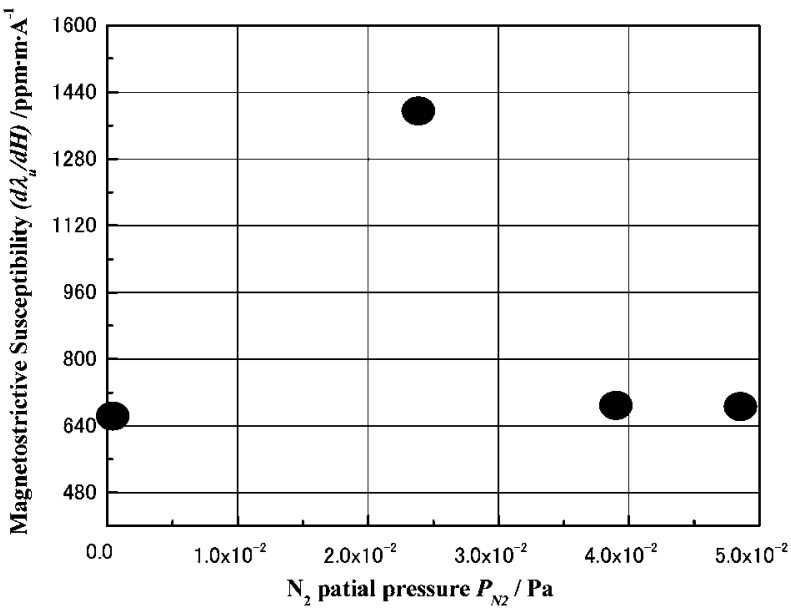

Fig. 3 Magnetostrictive susceptibility of $\mathrm{Sm}_{27} \mathrm{Fe}_{73}$ thin films prepared at different $\mathrm{N}_{2}$ partial pressure $P_{\mathrm{N}_{2}}$. 


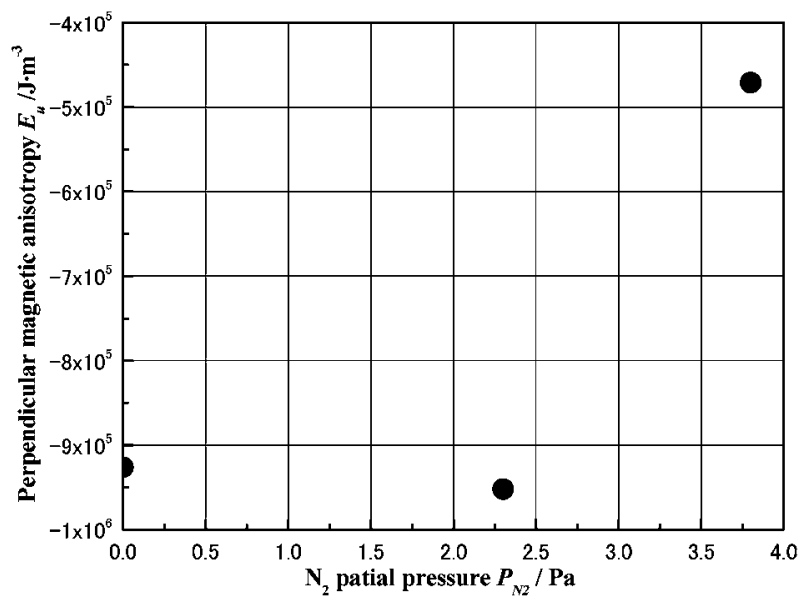

Fig. 4 Perpendicular magnetic anisotropy energy of $E_{\mathrm{u}}$ of $\mathrm{Sm}_{27} \mathrm{Fe}_{73}$ thin films prepared at different $\mathrm{N}_{2}$ partial pressure $P_{\mathrm{N}_{2}}$.

る11). 磁気弾性エネルギーの変化 $\Delta E_{\mathrm{me}}$ の結果から内部応力 $\sigma$ が負の值を示した. 従って, $\mathrm{Sm}_{27} \mathrm{Fe}_{73}$ 薄膜には圧縮の内 部応力が加わっていたと考えられる. 窒素が薄膜中に導入さ れる事によって, 压縮応力が増大し, 磁歪感受率が向上した と推察される.

一方, $P_{\mathrm{N}_{2}}=3.8 \times 10^{-3} \mathrm{~Pa}$ に颃いて作製した薄膜の磁歪感 受率は $P_{\mathrm{N}_{2}}=2.3 \times 10^{-3} \mathrm{~Pa}$ に比べ低下した. 酸化物や窒化物 の析出により $\mathrm{Sm}-\mathrm{Fe}$ 薄膜の最適組成から外れたため, $P_{\mathrm{N}_{2}}=$ $3.8 \times 10^{-3} \mathrm{~Pa}$ において作製した $\mathrm{Sm}_{27} \mathrm{Fe}_{73}$ 薄膜の磁歪感受率 の低下を招いたと考えられる18,19).

\section{4. 結言}

$\mathrm{DC}$ マグネトロンスパッタ法を用いた $\mathrm{Sm}-\mathrm{Fe}$ 薄膜の作製 に $\mathrm{Ar}, \mathrm{N}_{2}$ 混合ガスを用いる事によって, Sm-Fe 薄膜への窒 素ガス添加が磁歪特性へ及ぼす影響を検討した。Arのみに よって作製した $\mathrm{Sm}_{27} \mathrm{Fe}_{73}$ 薄膜は最も大きい飽和磁歪量を示 すのに対し， $P_{\mathrm{N}_{2}}=2.3 \times 10^{-3} \mathrm{~Pa}$ において最も高い磁歪感受 率を有する $\mathrm{Sm}_{27} \mathrm{Fe}_{73}$ 薄膜を得た。磁歪感受率の向上は, 窒 素添加による薄膜の圧縮内部応力の増加が, 垂直磁気異方性
エネルギーの減少を引き起こしたことが原因である事を明ら かにした。

本研究は東海大学未来科学技術共同研究センターのエコテ クノロジープロジェクトに拈いて遂行された. 東海大学の宮 本泰男氏, 小泉義晴博士に測定および分析の便宜をお図り頂 いた．ここに感謝の意を示す. 本研究は平成 16 年度科学研 究費補助金基盤研究 (c) (課題番号 16560616)により行われ た。

\section{文献}

1) A. E. Clark, in E. P. Wohifarth (ed.): Ferromagnetic Materials, 1, chap. 7, (North-Holland Publishing Company, 1980).

2) M. Sahashi and T. Kovayashi: J Acoustical Soc. Japan 466 (1990) 591-599.

3) V. Koeninger, Y. Matsumura, H. H. Uchida and H. Uchida: J. Alloy. Compd. 211/212(1994) 581-584.

4) M. Morimoto, T. Inagaki, T. Kobayashi, Y. Fujiwara, M. Masuda, S. Shiomi and T. Shiratori: Nippon Oyo Jiki Gakkaishi (in Japanese). 27 (2003) 269.

5) S. M. Na, S. J. Suh and S. H. Lim: J. Appl. Phys. 93 (2003) 8507.

6) T. M. Danh, N. H. Duc, H. N. Thanh and J. Teillet: J. Appl. Phys. 87 (2000) 7208

7) S. Esho and S. Fujiwara: AIP Conf. Proc. 34(1976) 331.

8) N. Heiman, A. Onton, D. F. Kyser, K. Lee and C. R. Guarniere: AIP Conf. Proc. 24(1975) 573.

9) R. Zwingman, W. L. Wilson, Jr. and H. C. Bourno: AIP Conf. Proc. 34 (1976) 334.

10) J. A. Tornton and D. W. Hoffman: Thin Solid Films 171(1989) $5-31$.

11) S. Tsunashima, H. Takagi, K. Kamegaki, T. Fujii and S. Uchiyama: IEEE Trans. Magn. MAG-14 (1978) 844-846.

12) M. Takeuchi, Y. Matsumura and H. Uchida: J. Japan Inst. Metals 69(2005) 667-670.

13) S. H. Lim, Y. S. Choi, S. H. Han, H. J. Kim, T. Shima and H. Fujimori: J. Magn. Magn. Mat. 189(1998) 1-7.

14) A. C. Tam and H. Schroeder: IEEE Trans. Magn. 25(1989) 2629 .

15) K. Muramatsu, T. O. Yamaki, N. Matsuoka, M. Takeuchi, Y. Matsumura and H. Uchida: J. Alloy. Comp. 408-412(2006) 335-339.

16) A. Kadowaki, S. Masuda, Y. Matsumura and Y. Nishi: J. Japan Iast Metals 69(2005) 377-379.

17) H. Hauser: J. Appl. Phys. 75 (1994) 2584-2597.

18) T. Miyazaki, S. Yamaguchi, M. Takahashi, A. Yoshihara, T. Shimamori and T. Wakiyama: J. Magn. Magn. Mat. 75(1992) $243-251$.

19) T. Honda, U. Hayashi, K. I. Arai, K. Ishiyama and M. Yamaguchi: IEEE Trans. Magn. 29(1993) 3126-3128. 